\title{
Erratum to: Influence of Processing Conditions and Material Properties on Electrohydrodynamic Direct Patterning of a Polymer Solution
}

\author{
SHIN JANG, ${ }^{1}$ YEONGJUN KIM, ${ }^{1}$ and JE HOON OH ${ }^{1,2}$ \\ 1.-Department of Mechanical Engineering, Hanyang University, 55 Hanyangdaehak-ro, \\ Sangrok-gu, Ansan, Gyeonggi-do 426-791, Korea. 2.-e-mail: jehoon@hanyang.ac.kr
}

\section{ERRATUM TO: Journal of ELECTRONIC \\ MATERIALS \\ DOI: 10.1007/S11664-015-4252-0}

During the correction process, errors were introduced to the scale bars in Fig. 5 . The correct Fig. 5 is given below. 

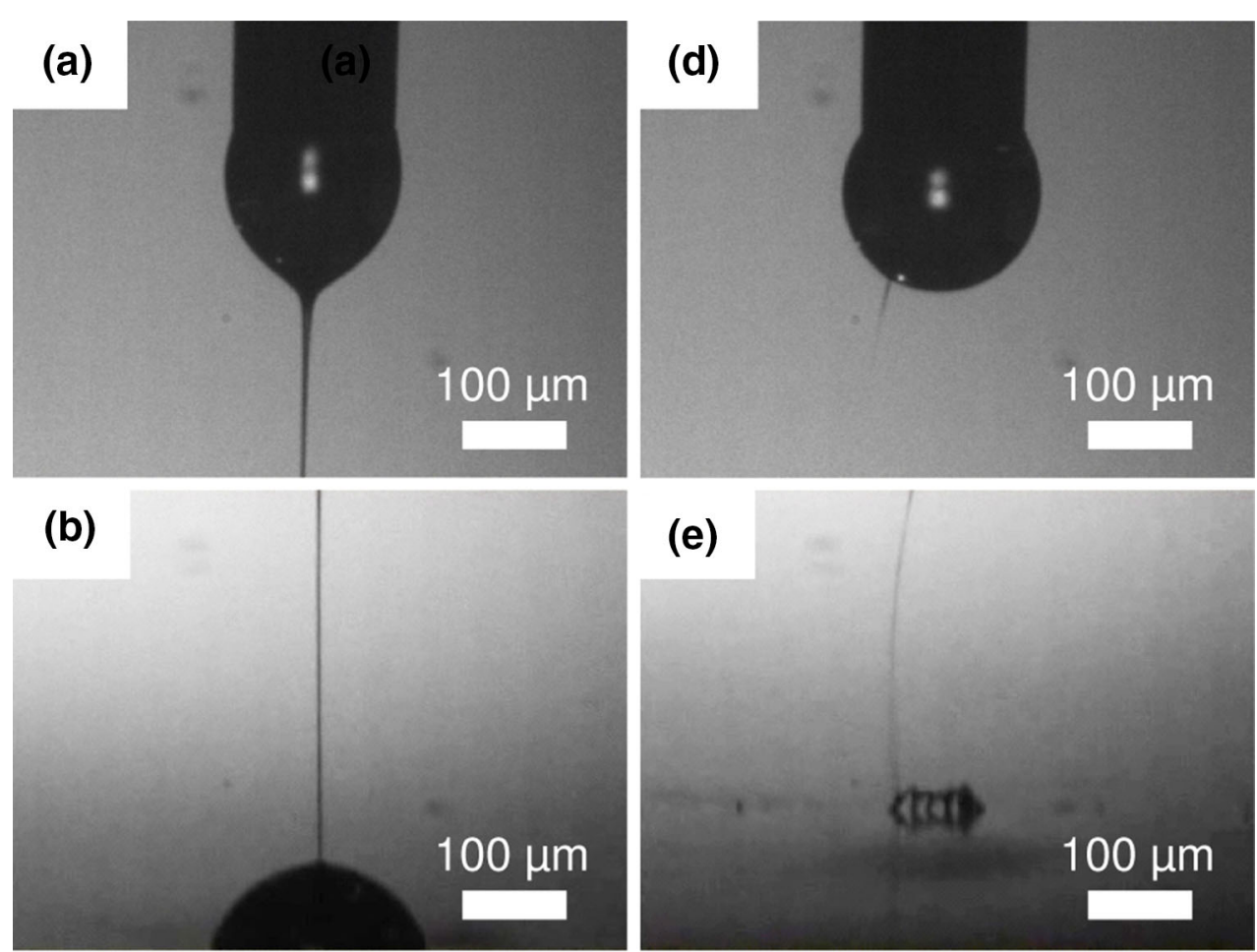

(e)
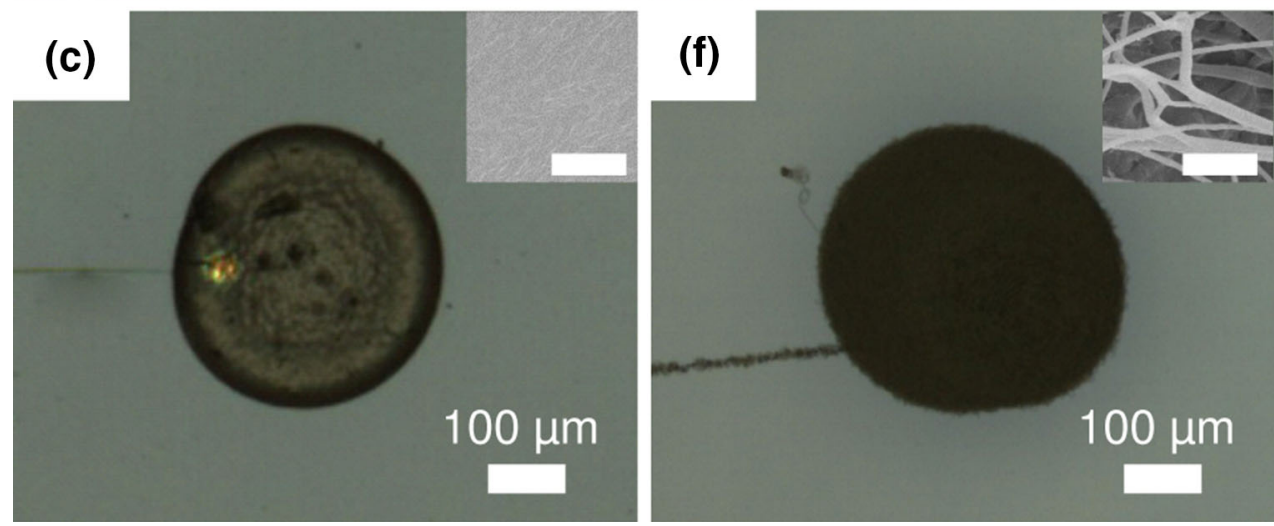

Fig. 5. Jet behaviors, jet deposition shapes, and resultant patterns on the stationary substrate for the 6 wt. $\%$ PEO $\left(M_{v}=60 \times 10^{4}\right)$ solution at two different $R$ values: (a-c) $R=0.64$ and (d-f) $R=0.45$. Scale bars in the insets of (c) and (f) are $100 \mathrm{~nm}$. 